\title{
ENERGY ABSORPTION PERFORMANCE OF A RAIN FOREST VEHICLE UNDER FRONTAL IMPACT
}

\author{
Z. Ahmad and M.S. Othman \\ Computational Solid Mechanics Laboratory (CSMLab) \\ Faculty of Mechanical Engineering, Universiti Teknologi Malaysia, \\ 81310 UTM Skudai, Johor, Malaysia \\ Phone : +607-553-4806 \\ Email: syauqy88@gmail.com
}

\begin{abstract}
This paper presents a comprehensive numerical study of the crashworthy design of a rain forest vehicle (RFV) subjected to impact loading. A commercial finite element (FE) nonlinear code, LSDYNA, was employed to further evaluate the energy absorption performance of the structure under two crash scenarios; impacting a rigid wall and a rigid pole. The simulation results were used to identify the energy absorption capacity of the main subcomponent, thus facilitating crashworthiness requirements for future design improvements. The aims of this investigation were to enhance understanding of RFV behavior under impact loading and improve energy absorption capacity and safety, which will contribute towards the development of an early design stage of the RFV, and design and evaluation that may lessen the need for destructive full-scale testing. Recommendations and suggestions for improving the energy absorption capacity of RFVs have been made. A considerable improvement in energy absorption capacity has been obtained by inclusion of a supplementary device attached to the main chassis. These simplified provisions provide design guidelines that will considerably improve an operator's chances of survival during an accidental impact in the forest.
\end{abstract}

Keywords: Finite element; crash analysis; crashworthiness; vehicle; simulation.

\section{INTRODUCTION}

Heavy vehicles used in rural, mining, and construction industries are susceptible to impact loads, as they have a higher center of gravity and commonly operate on off-road terrain (Thambiratnam, Clark, \& Perera, 2008). In military situations, a heavy vehicle such as a Rain Forest Vehicle (RFV) always operates in off-road conditions. A Rain Forest Vehicle (RFV) is defined as an outdoor vehicle that can be operated in rural areas by the military especially in the forest. This vehicle has four wheels and has a greater stability for operating on uneven terrain and sloping conditions ( $\mathrm{Hu}, \mathrm{Lu}, \& \mathrm{Lu}, 2011)$. Taking into account the condition of the forest and level of safety, the frontal part of the RFV must be able to absorb some of the kinetic energy (KE) and maintain a survival zone when impacted with obstacles or forest trees. The design and analysis of an RFV is complex and requires dual criteria of adequate flexibility to absorb energy and adequate stiffness to maintain a survival zone around the operator. Controlling the crash response of the vehicle without any encroachment into the survival space are the main elements of vehicle safety (Du Bois et al., 2004; Kamal \& Rahman, 2012; Kamal, Rahman, \& Sani, 2013). Many researchers (Ahmad, Nagel, \& Thambiratnam, 2013; Ahmad \& Thambiratnam, 2009; Clark, Thambiratnam, \& Perera, 2008; Rahman, Ariffin, 
Abdullah, \& Jamaludin, 2007; Rahman, Ariffin, Jamaludin, Abdullah, \& Noor, 2008) have been employing the finite element method to enhance the safety level of vehicles in the event of impact.

Research into off-road vehicles is limited, and sparse to date. As such, some existing research involving vehicles impacting with rigid barriers and poles is addressed in the present investigation for the sake of comparison of research approaches. Gursel and Nane (2010) have compared two car models, the Dodge Intrepid and Ford Taurus, and run crash tests using the finite element method. This method aims to minimize the number of crash tests required when designing a vehicle. (Zaouk, Bedewi, Kan, \& Marzougui, 1996) have evaluated the impact of Chevrolet C-1500 on a rigid barrier using FE software, LSDYNA. This software has also been used by Cheng et al. (2001) to investigate the effects of applying different crash scenarios to the 1997 Honda Accord DX. For impacting rigid poles, Hu et al. (2011) analyzed the crash simulation of an off-road utility vehicle and identified the energy absorption and acceleration of human dummies.

A small number of off-road vehicles has been designed considering only the stiffness of the structures under static loads (Rahman, Mohyaldeen, Noor, Kadirgama, \& Bakar, 2011; Yang, Wu, \& Hamada, 2013). The reasons for the exclusion are attributed to a lack of knowledge and information about the behavior of these structures in the post-yield region and their energy-absorption capacity. From an energy absorption point of view, the crashworthiness performance of the structure may not be omitted in designing a vehicle since it is paramount to reducing the number of casualties resulting from an impact event. As such, the present study is a numerical study of a designed RFV using commercial explicit nonlinear finite element code LS-DYNA. The aims of this investigation are to (1) enhance our understanding of RFV behavior under impact loading, (2) improve energy absorption capacity and safety, and (3) generate research information, which will contribute to the development of an early design stage of an RFV for evaluation that may lessen the need for destructive full-scale testing. Two crash scenarios are simulated in an off-road environment: a vehicle impacting a rigid barrier, and a pole. From the research outcomes, recommendations and suggestions for improving the energy absorption capacity of RFVs have been made. These simplified provisions provide design guidelines that will considerably improve an operator's chances of survival during an accidental impact in the forest.

\section{MODEL DESCRIPTION}

\section{Finite element RFV model}

Figure 1 depicts the finite element model of an RFV, which consists of 278 different parts. The RFV model has a total length of $4960 \mathrm{~mm}, 2200 \mathrm{~mm}$ width, and $1800 \mathrm{~mm}$ height and the total body mass is $2900 \mathrm{~kg}$. The FE model was meshed using the four node Belytschko-Tsay shell element. Overall this model consists of 84,199 shell elements and 85,738 nodes. The material model was defined by a piecewise linear plasticity behavior (refer to Figure 2) and Blatz-Ko rubber only for the tires. The connections between parts were modelled with nodal constraints. Two types of nodal constraint were employed, constrained nodal rigid bodies and spot welds. The contact interaction between the parts of the RFV was defined using the automatic single surface contact algorithm with static and dynamic coefficients of 0.3 and 0.2 , respectively. The 
termination time was set to $60 \mathrm{~ms}$ with an applied initial velocity of $15 \mathrm{~m} / \mathrm{s}(54 \mathrm{~km} / \mathrm{h})$ for scenarios impacting rigid walls and poles.

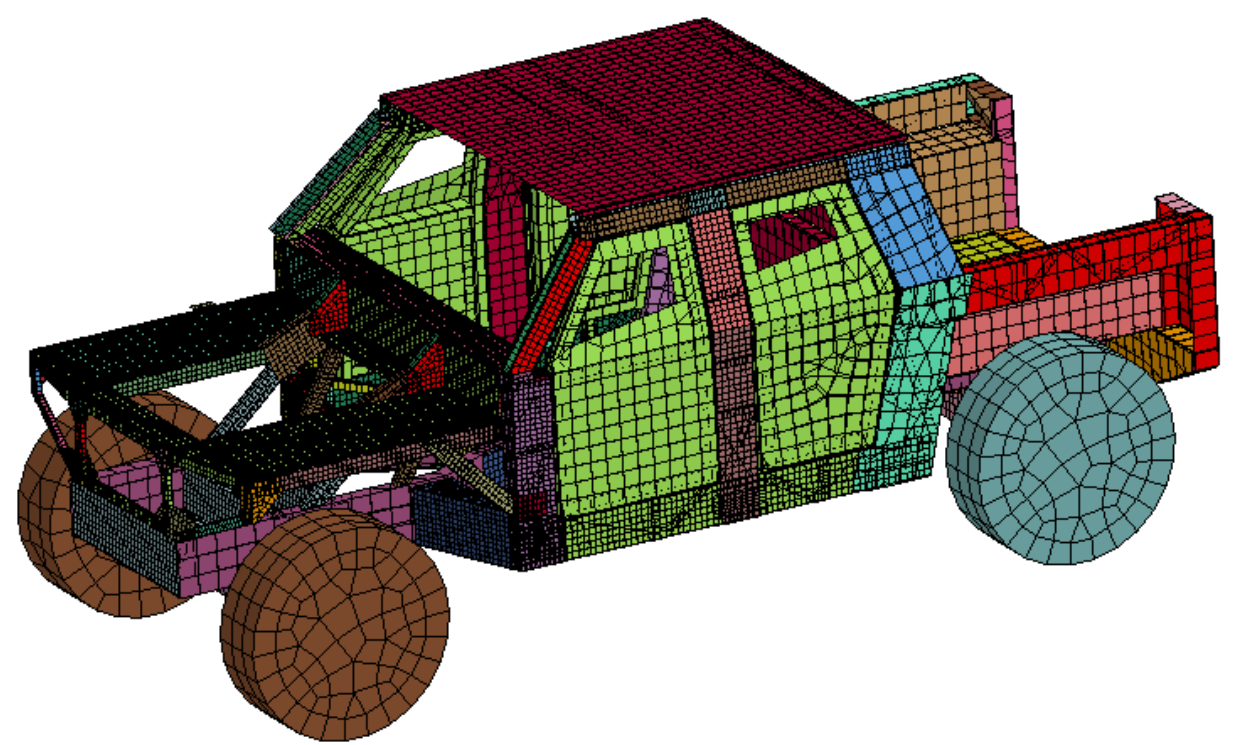

Figure 1. The finite element model RFV

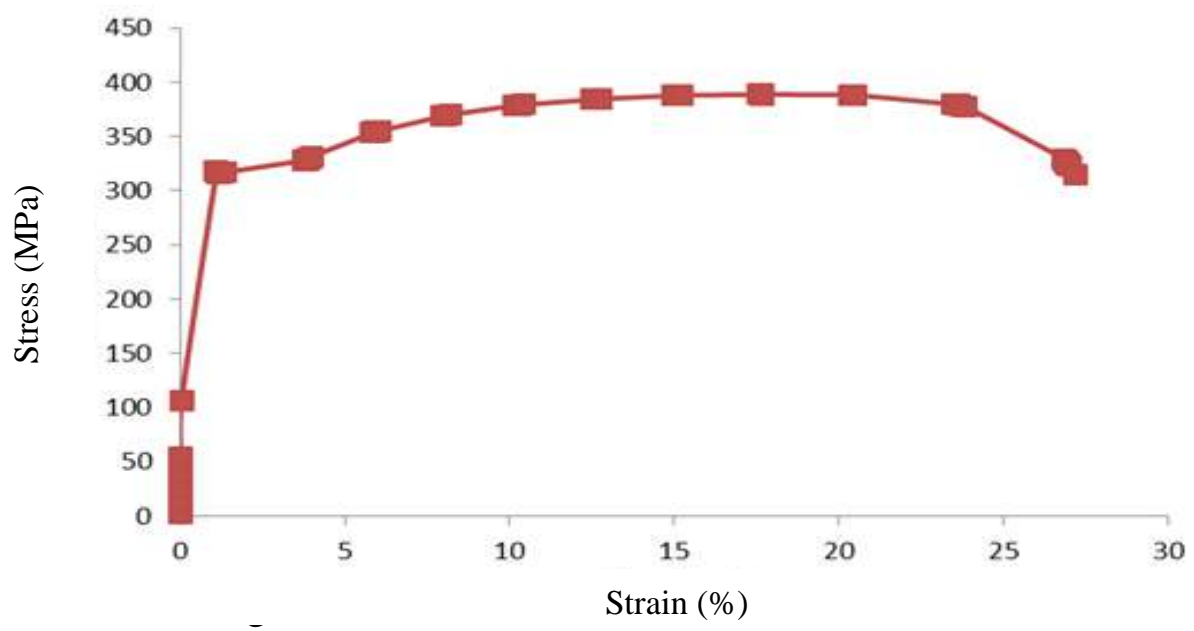

In the present simulation, the rigid wall is defined by a planar shell element with all nodes fully constrained which restricts movement in all directions. The rigid pole is defined by a solid cylinder, by constraining all the nodes at the bottom surface. The diameter of the pole is $800 \mathrm{~mm}$ and is placed at the center of the impact point. This crash scenario represents the vehicle impacting a tree. Parts A, B, C and D in Figure 3 show the longitudinal members of the RFV with higher energy absorption capacity. Parts A, $\mathrm{B}, \mathrm{C}$ and $\mathrm{D}$ denote the cross column, end longitudinal column, frontal longitudinal column and chassis, respectively. 


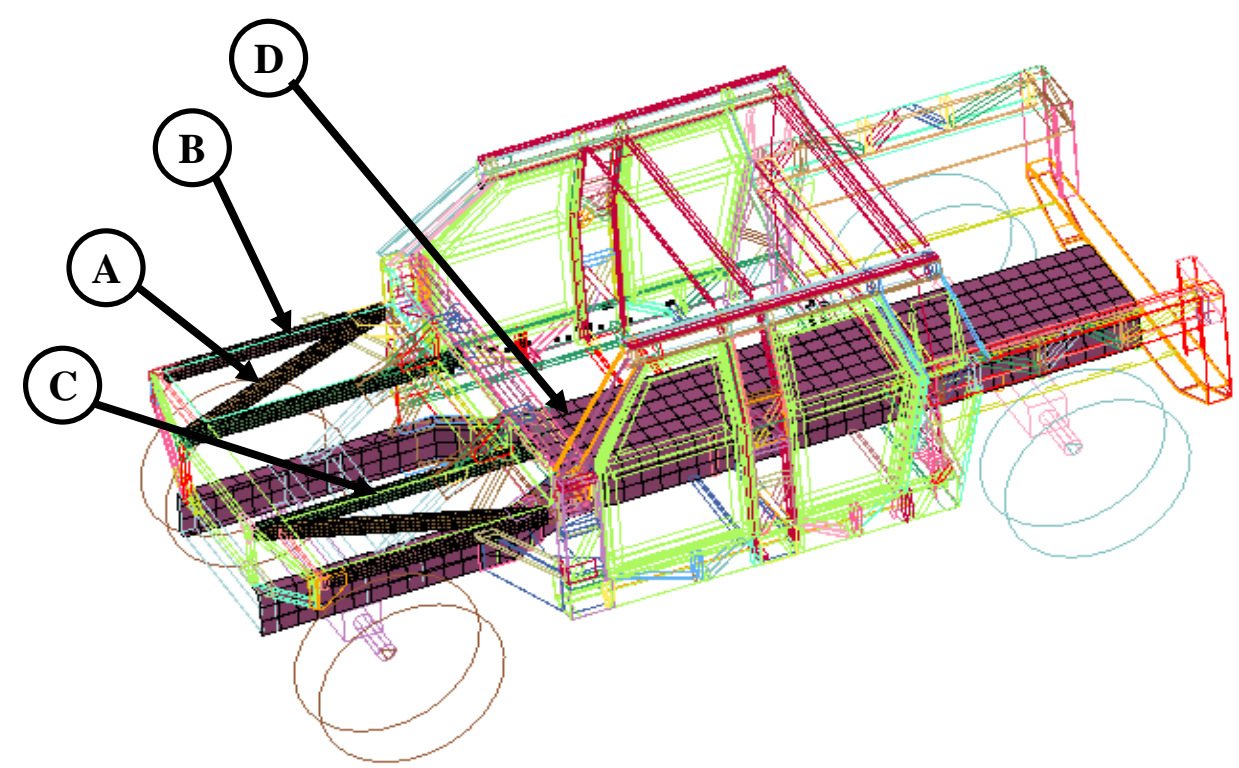

Figure 3. Longitudinal parts

\section{NUMERICAL RESULTS AND DISCUSSION}

\section{Full Frontal Rigid Wall}

Figure 4 shows the deformation of the FE model at times of 0, 20, 4 and 60ms. From a crashworthiness point of view, deformation of the structure must take place in the frontal zone only through progressive crushing. The safety compartment must be sufficiently maintained to avoid any encroachment of the frontal components and the transferred impact load should be minimized. Figure 4 shows that the frontal parts start to crumple at $20 \mathrm{~ms}$. Furthermore, as the impact duration increases to $40 \mathrm{~ms}$, both sides of the frontal structure initiate vertical bending. Due to the presence of bending modes, the section flange starts to buckle locally by initiating the plastic hinge mechanism. The simulation was stopped at $60 \mathrm{~ms}$. Figure 5 shows the distribution of Von Mises stress at $60 \mathrm{~ms}$. It is noteworthy that the maximum stress occurs at critical points where there is severe folding and bending deformations. Part D has deformed in a progressive crush and is more excessive than with the bending onset of $40 \mathrm{~ms}$. A further improvement has been made to retrofit this primary structural component of the RFV.

Figure 6 denotes the internal energy of frontal longitudinal members up to $60 \mathrm{~ms}$. Part D has the highest energy absorption capacity of 56kJ followed by $\mathrm{C}, \mathrm{A}$ and $\mathrm{B}$, at about $31.6 \mathrm{~kJ}, 23.3, \mathrm{~kJ}$ and $13.5 \mathrm{~kJ}$, respectively. The simulation shows that the maximum crash energy was absorbed by the front part of the vehicle and only minimal impact energy was transferred to other components. From the trend line at D, before $10 \mathrm{~ms}$, part $\mathrm{D}$ exhibits the highest gradient due to the initiation process of the deformational structure. It then continues to dramatically increase as the progressive crushing progresses. In this crash case, the chassis has absorbed the highest impact energy, since it is purposely designed to absorb most of the impact energy and maintain the passenger compartment. Similar findings can be found in previous research into passenger vehicles (Jenefeldt \& Thomson, 2004). 


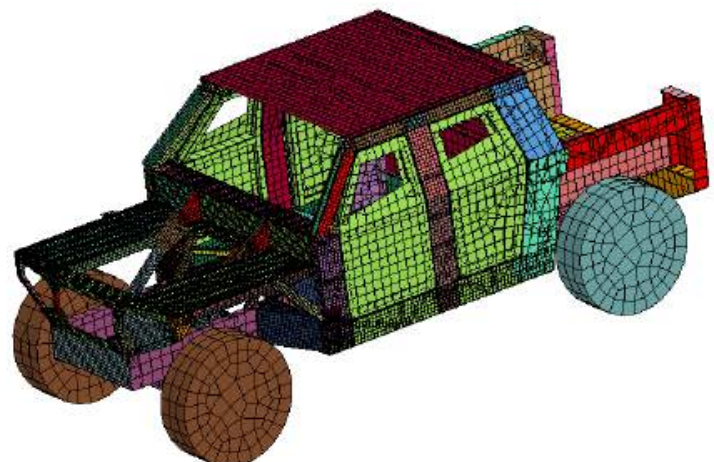

a) $\mathrm{t}=0 \mathrm{~ms}$

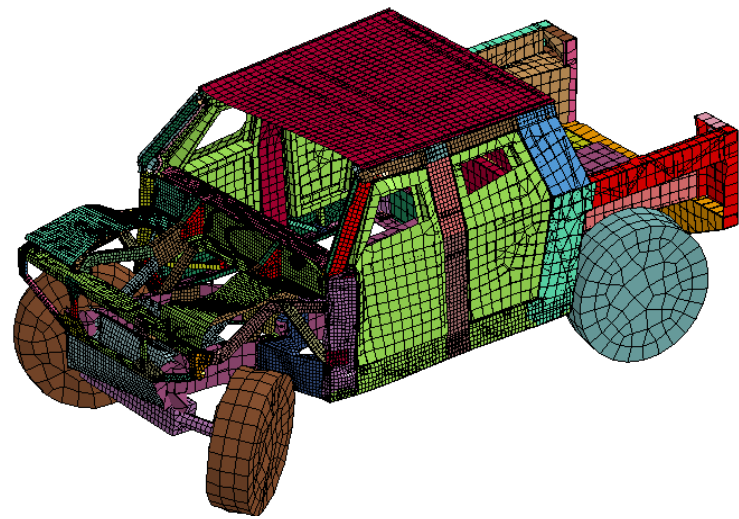

c) $\mathrm{t}=40 \mathrm{~ms}$

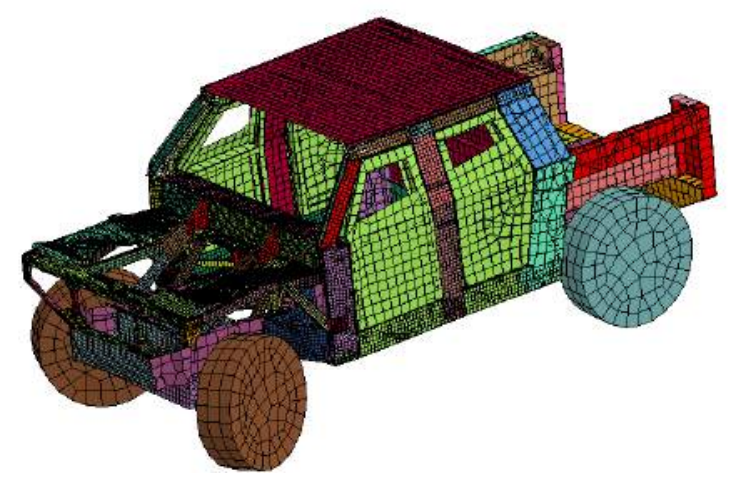

b) $\mathrm{t}=20 \mathrm{~ms}$

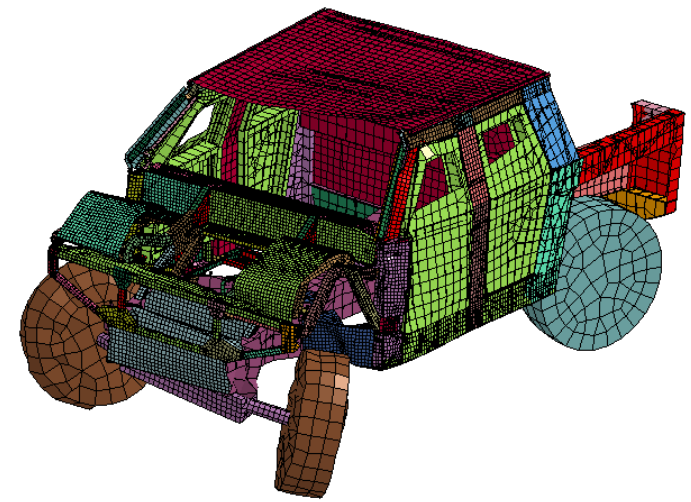

d) $\mathrm{t}=60 \mathrm{~ms}$

Figure 4. Deformations of the models in full frontal impact simulations

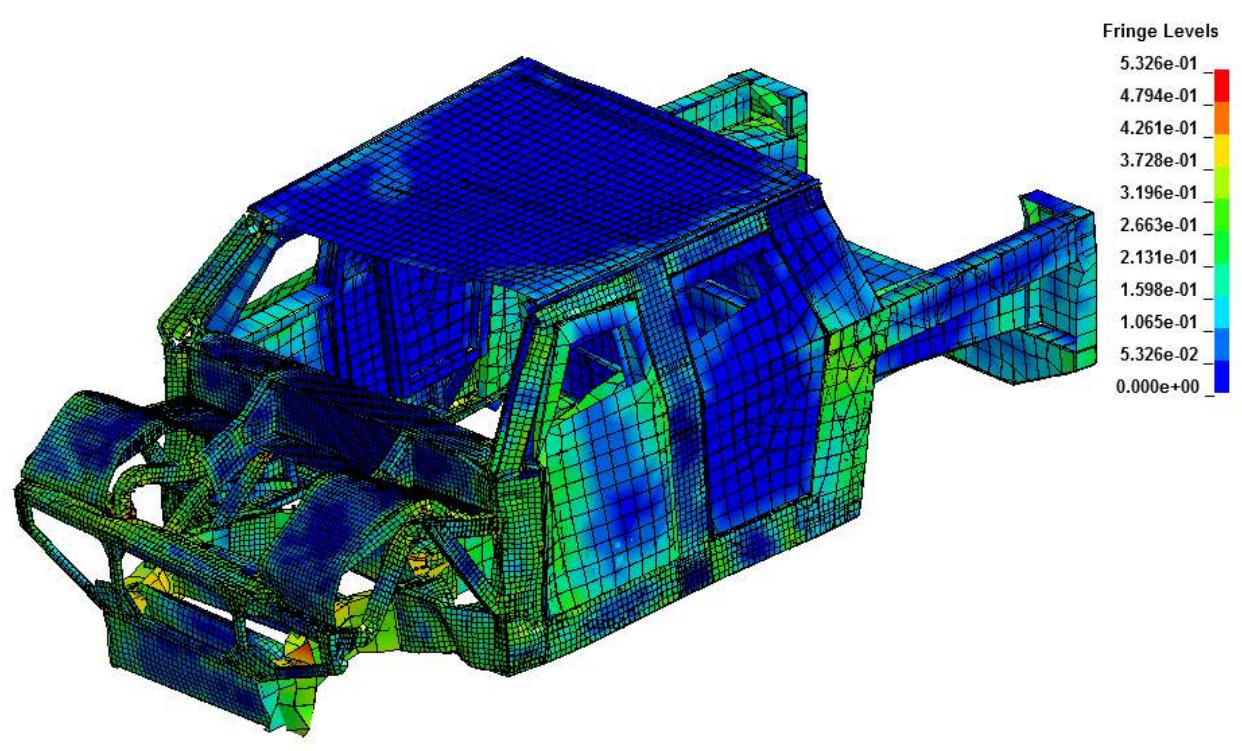

Figure 5. von Mises tress at $60 \mathrm{~ms}$. 


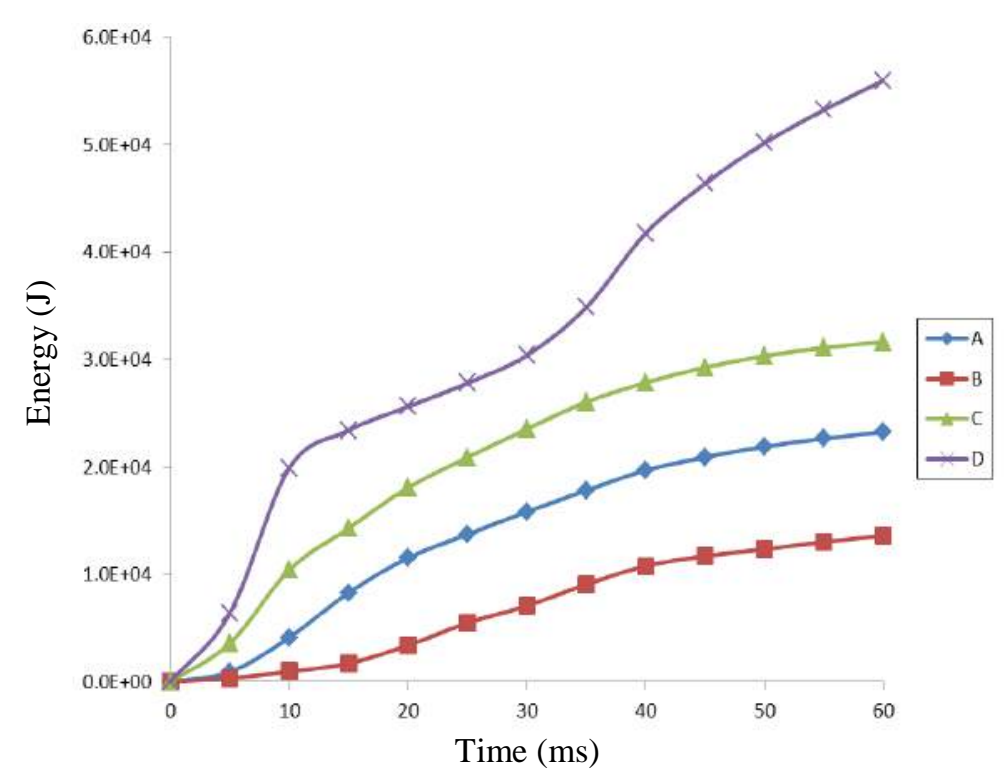

Figure 6. Internal energy of different parts

\section{Rigid Pole}

In the rigid pole impact, the FE model simulated the RFV impacting the stationary rigid pole at $15 \mathrm{~m} / \mathrm{s}$. Figure 7 shows the deformation of the RFV under such loading at an impact duration of $0,20,40$, and $60 \mathrm{~ms}$. This simulation shows that the safety compartment has less deformation compared to when impacting the rigid wall. In particular, the A pillar, toepan and dashboard have not deformed. It is evident that deformation has taken place only at the front crushable zone. Furthermore, Part C or the frontal longitudinal columns, have deformed severely under progressive deformation followed by bending, thus resulting in the highest energy absorption. It is worth noting that this FE model is capable of maintaining the safety compartment when impacted to a rigid pole. It shows that this numerical result has agreed well with the previous research on vehicles impacting on-road pole (Hong et al., 2008; Hu et al., 2011).

Figure 8 shows the energy absorbed by the different parts when impacting a rigid pole. $\mathrm{C}$ is the nearest to the impact zone, thus resulting in a higher energy absorption capacity of about $37.1 \mathrm{~kJ}$, followed by D, A and B. However, Part C has deformed more compared to the others. These structures deformed under buckling mode after reaching a critical value and a plastic hinge mechanism has later developed in the material. The moment distribution continues to vary as the additional plastic hinges are developed. Part B has the lowest energy absorption capacity due to its location in this crash scenario. It was also subjected to bending in accordance with the pole circumferences. Part D (chassis) has also deformed in a progressive manner although the energy has been transferred to the middle point of the compartment. Due to this weak structure, Part D needs to be reinforced, as also suggested by Ghannam, Niesluchowski, and Culkeen (2002) (Figure 9). 


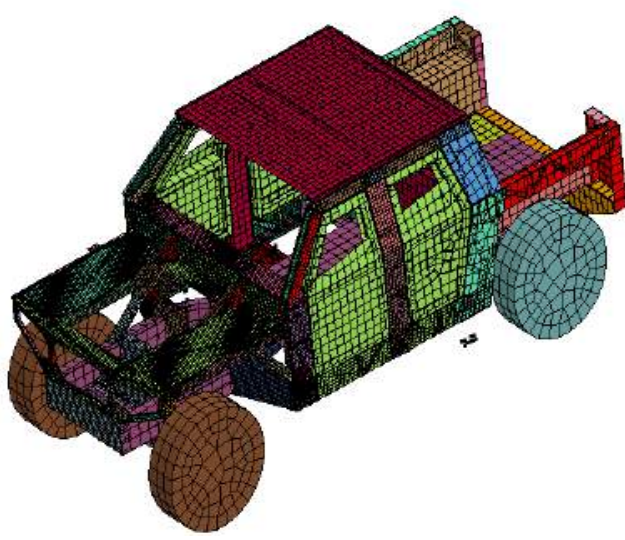

a) $\mathrm{t}=0 \mathrm{~ms}$

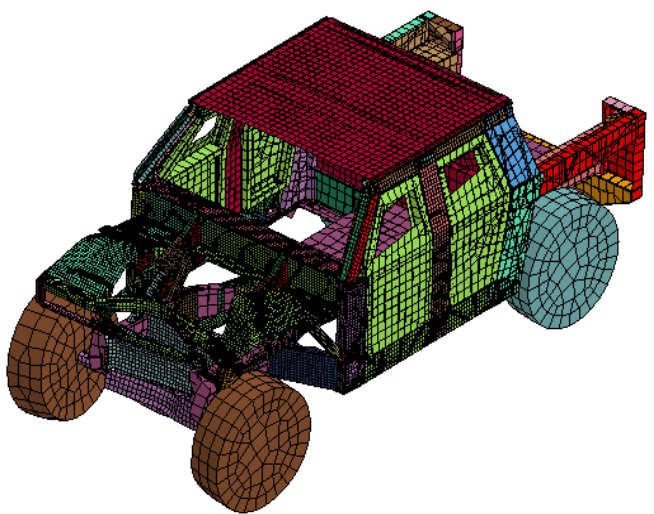

c) $\mathrm{t}=60 \mathrm{~ms}$

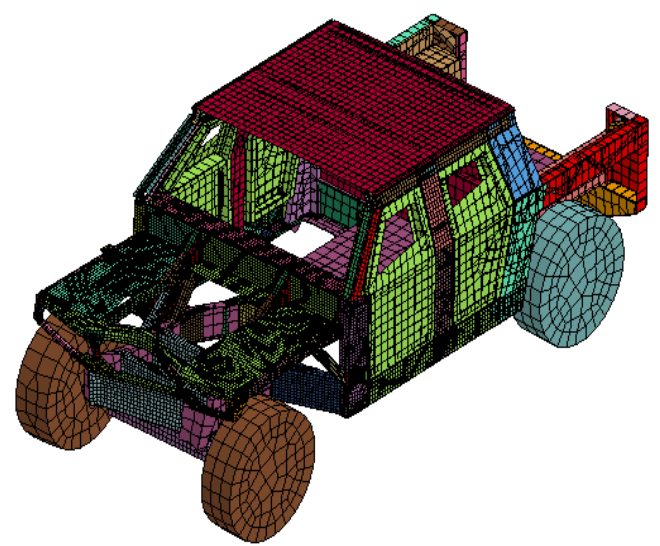

b) $\mathrm{t}=20 \mathrm{~ms}$

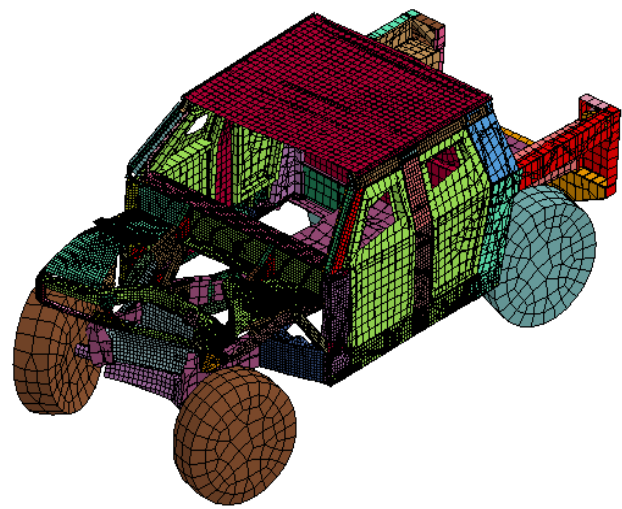

d) $\mathrm{t}=90 \mathrm{~ms}$

Figure 7. The deformation of the model in a rigid pole simulation

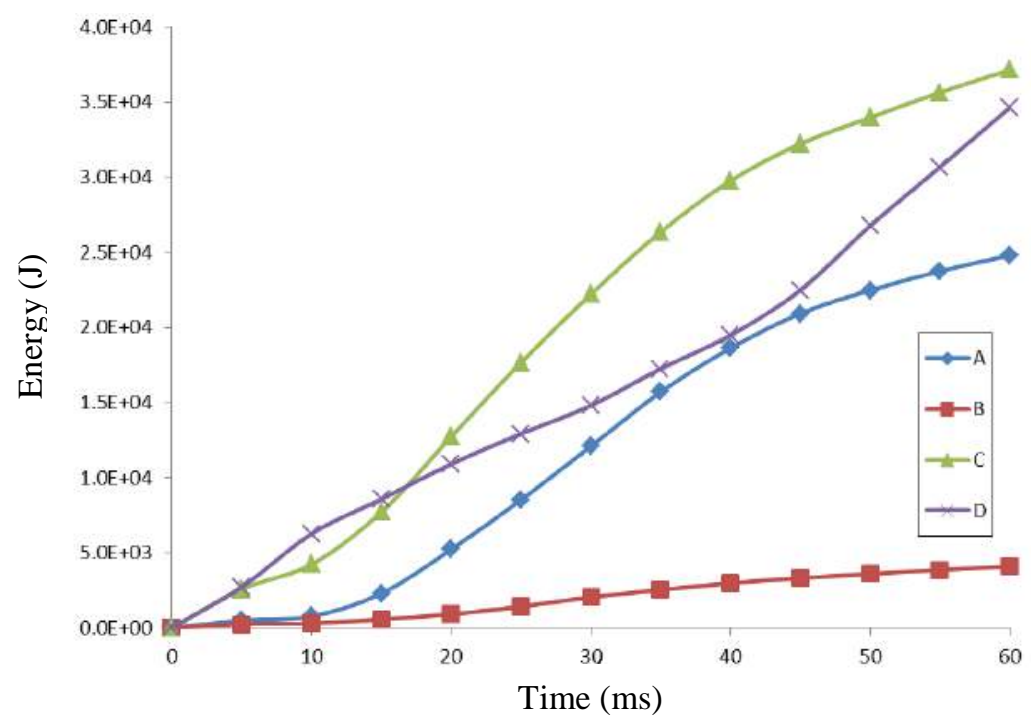

Figure 8. Internal energy of different parts 


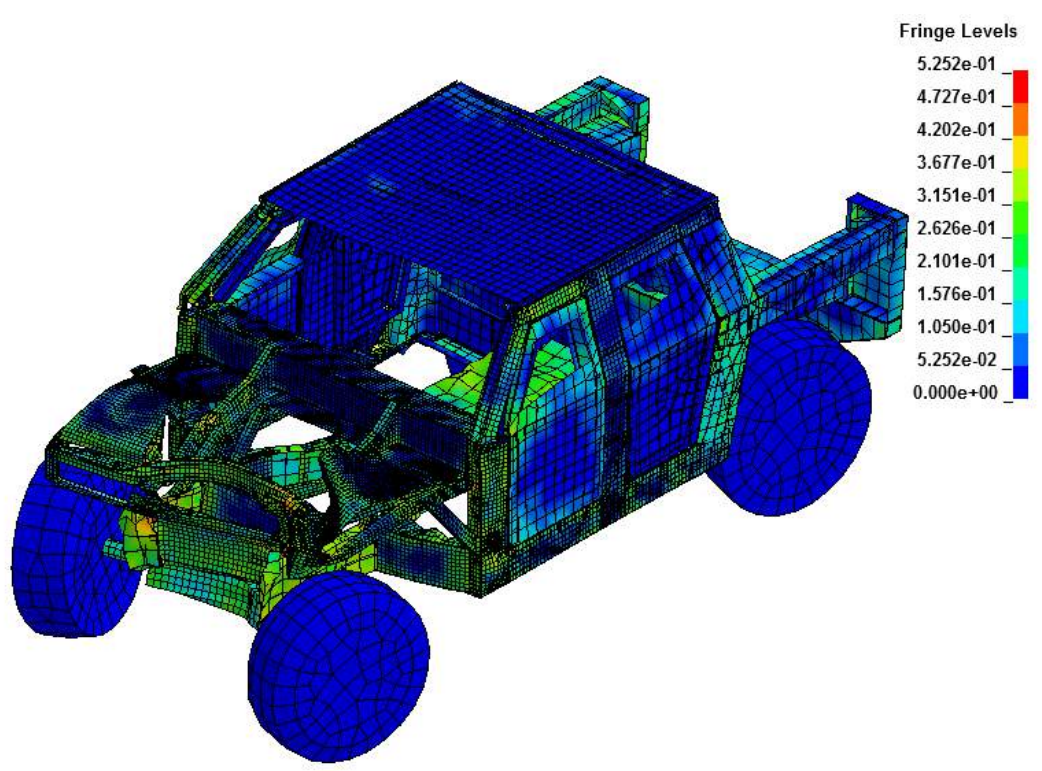

Figure 9. Von Mises Stress at 60ms.

\section{STRUCTURAL IMPROVEMENT}

From the abovementioned results, it could be concluded that the primary energy absorbing component is Part D which is the chassis. Structural reinforcement has thus been performed for this chassis by retrofitting some additional parts. This should be advantageous since this primary component has shown great ability to absorb impact energy. Figure 10 indicates the location of improvement on the RFV chassis. Most importantly, an insignificant mass contribution has been ensured for this reinforcement. Table 1.0 describes the additional components and their location. By retrofitting this component, the RFV has become stiffer, with a higher energy absorption capacity as well as great crashworthy behavior as evident in Figure 11. For the sake of brevity, only the numerical results of full frontal impact are presented in this section.

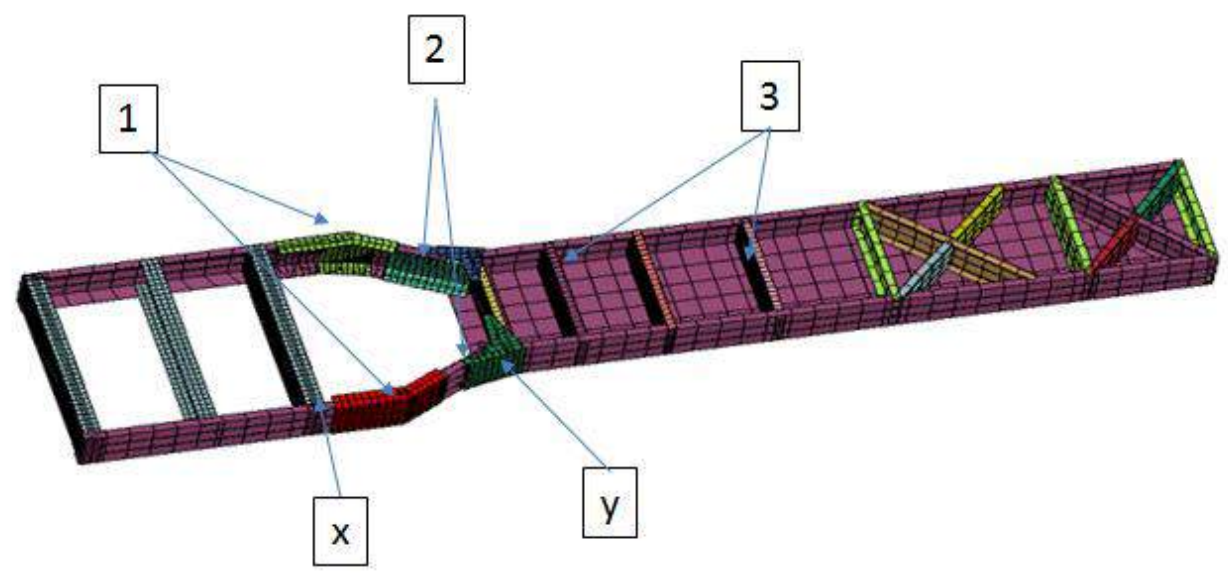

Figure 10. Retrofitted location of RFV chassis 
Table 1.0. Description and location of structural re-improvement

\begin{tabular}{cll}
\hline No & \multicolumn{1}{c}{ Part } & \multicolumn{1}{c}{ Description } \\
\hline 1 & Rear bending support & $\begin{array}{l}\text { Increase the stiffness of the part and prevent } \\
\text { initial bending }\end{array}$ \\
2 & Inner support 2 & $\begin{array}{l}\text { Increase the stiffness in the critical region } \\
\text { during bending }\end{array}$ \\
3 & $\begin{array}{l}\text { Passenger compartment } \\
\text { cross members 2 and } 4\end{array}$ & $\begin{array}{l}\text { Maintain the passenger compartment and } \\
\text { minimize deformation }\end{array}$ \\
$\mathrm{x}$ & Engine cross member 3 & $\begin{array}{l}\text { Increase the distance between the second plate } \\
\text { holder about 225mm, to increase bending } \\
\text { resistance } \\
\text { Move backward to strengthen the Inner } \\
\text { Support 2 and to increase the joint }\end{array}$ \\
\hline
\end{tabular}

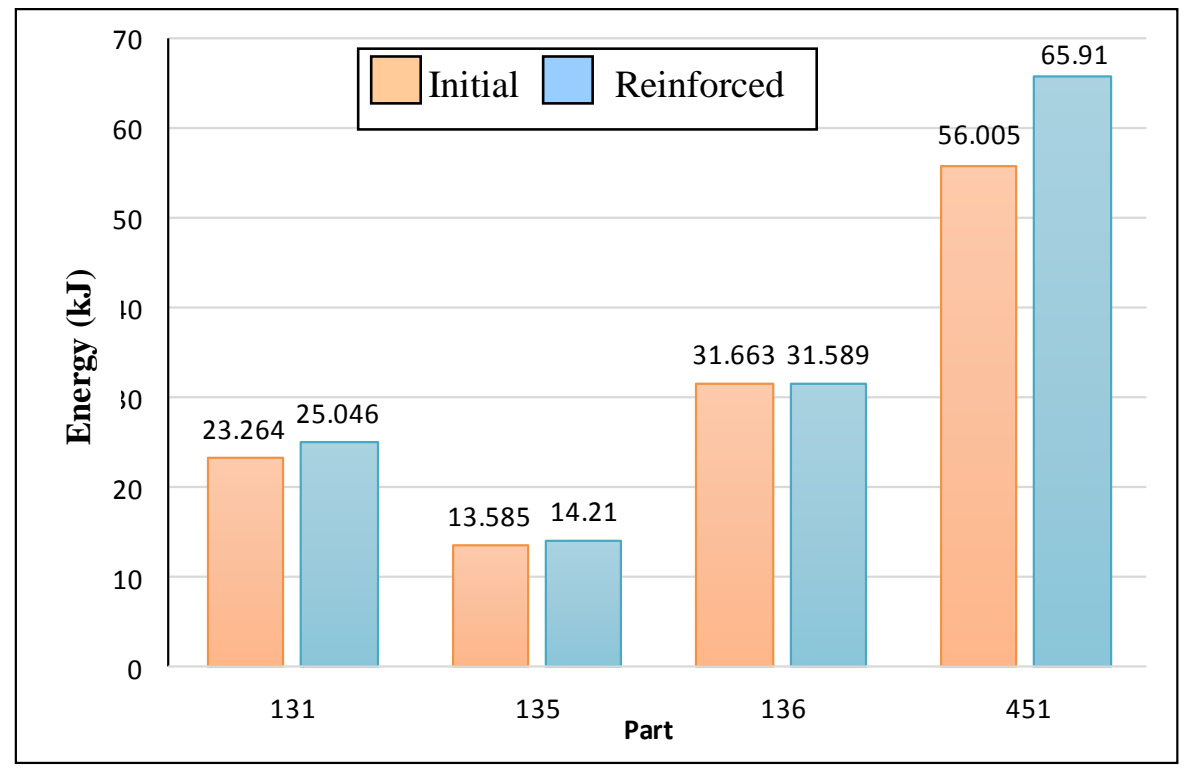

Figure 11. Comparison of energy absorption capacity for initial and reinforced design of RFV chassis under full frontal impact

\section{CONCLUSIONS}

Through the simulation of full frontal, it is evident that Part D, or the chassis of the structure, has experienced progressive crushing in combination with bending and buckling modes resulting in excessive deformation. A higher energy absorption capacity of about $56 \mathrm{~kJ}$ at $60 \mathrm{~ms}$ was thus obtained. Obviously, the chassis stiffness and strength is insufficient to sustain the survival room in impact loading. This crush response may be attributed to the non-progressive crushing of the individual structural components. In impacting rigid pole scenario, Part $\mathrm{C}$ or the frontal longitudinal has the highest energy absorption capacity of $37.1 \mathrm{~kJ}$ compared to others, partly due to the availability of the crush zone. However, Part D has detrimentally deformed towards the passenger compartment and has been reinforced appropriately for structural improvement. The 
proposed structural improvement may be advantageous in the future development of off-road vehicles.

\section{ACKNOWLEDGEMENTS}

The authors would like to thank the Faculty of Mechanical Engineering at the Universiti Teknologi Malaysia and Universiti Teknologi Malaysia for financial support under Research University Grants QJ130000.7124.01J75 and QJ130000.2524.04H82. The authors are also grateful to Innopeak Sdn Bhd.

\section{REFERENCES}

Ahmad, Z., Nagel, G., \& Thambiratnam, D. (2013). Inclusion of tapered tubes in enhancing the crash performance of automotive frontal structures. Key Engineering Materials, 553, 1-6.

Ahmad, Z., \& Thambiratnam, D. P. (2009). Application of foam-filled conical tubes in enhancing the crashworthiness performance of vehicle protective structures. International Journal of Crashworthiness, 14(4), 349-363.

Cheng, Z. Q., Thacker, J. G., Pilkey, W. D., Hollowell, W. T., Reagan, S. W., \& Sieveka, E. M. (2001). Experiences in reverse-engineering of a finite element automobile crash model. Finite Elements in Analysis and Design, 37(11), 843860.

Clark, B. J., Thambiratnam, D. P., \& Perera, N. J. (2008). Enhancing the impact energy absorption in roll over protective structures. International Journal of Crashworthiness, 13(2), 167-183.

Du Bois, P., Chou, C. C., Fileta, B. B., Khalil, T. B., King, A. I., Mahmood, H. F.et al.Belwafa, J. E. (2004). Vehicle crashworthiness and occupant protection. Paper presented at the Automotive Applications Committee American Iron and Steel Institute, Southfield, Michigan.

Ghannam, M. Y., Niesluchowski, M., \& Culkeen, P. M. (2002). Analysis of a frontal rail structure in a frontal collision: SAE Technical Paper.

Gursel, K. T., \& Nane, S. N. (2010). Non-linear finite element analyses of automobiles and their elements in crashes. International Journal of Crashworthiness, 15(6), 667-692.

Hong, S. W., Park, C. K., Mohan, P., Morgan, R. M., Kan, C. D., Lee, K.et al.Bae, H. (2008). A study of the iihs frontal pole impact test (Vol. 1): SAE Technical Paper.

Hu, H., Lu, W. J., \& Lu, Z. (2011). Impact crash analyses of an off-road utility vehicle part ii: Simulation of frontal pole, pole side, rear barrier and rollover impact crashes. International Journal of Crashworthiness, 17(2), 163-172.

Jenefeldt, F., \& Thomson, R. (2004). A methodology to assess frontal stiffness to improve crash compatibility. International Journal of Crashworthiness, 9(5), 475-482.

Kamal, M., \& Rahman, M. M. (2012). Study on dynamic behaviour of wishbone suspension system.

Kamal, M., Rahman, M. M., \& Sani, M. S. M. (2013). Application of multibody simulation for fatigue life estimation. International Journal of Automotive and Mechanical Engineering, 7(1), 912-923. 
Rahman, M. M., Ariffin, A. K., Abdullah, S., \& Jamaludin, N. (2007). Finite element based durability assessment of a free piston linear engine component SDHM Structural Durability and Health Monitoring (Vol. 3, pp. 1-13).

Rahman, M. M., Ariffin, A. K., Jamaludin, N., Abdullah, S., \& Noor, M. M. (2008). Finite element based fatigue life prediction of a new free piston engine mounting. Journal of Applied Sciences, 8(9), 1612-1621.

Rahman, M. M., Mohyaldeen, H. M., Noor, M. M., Kadirgama, K., \& Bakar, R. A. (2011). Linear static response of suspension arm based on artificial neural network technique Advanced Materials Research (Vol. 213, pp. 419-426).

Thambiratnam, D. P., Clark, B. J., \& Perera, N. J. (2008). Dynamic response of a rollover protective structure. Computer-Aided Civil and Infrastructure Engineering, 23(6), 448-464.

Yang, Y., Wu, X., \& Hamada, H. (2013). Application of fibre-reinforced composites beam as energy absorption member in vehicle. International Journal of Crashworthiness, 18(2), 103-109.

Zaouk, A. K., Bedewi, N. E., Kan, C. D., \& Marzougui, D. (1996). Development and evaluation of a c-1500 pickup truck model for roadside hardware impact simulation. Paper presented at the Proceedings of the FHWA Vehicle Crash Analysis Crash Conference, Mclean, VA. 